Volume 14 - Número 2 - ago/dez de 2019

\title{
UNVEILING THE LAYERS OF THE L.O.L. SURPRISE DOLL: A LINGUISTIC ANALYSIS THROUGH THE GRAMMAR OF VISUAL DESIGN
}

\section{REVELANDO AS CAMADAS DA EMBALAGEM DA BONECA L.O.L. SURPRISE: UMA ANÁLISE LINGUIISTICA À LUZ DA GRAMÁTICA DO DESIGN VISUAL}

\author{
Danielle Barbosa Lins de Almeida ${ }^{1}$ \\ Polianna Ferreira da Silva Torres ${ }^{2}$
}

\begin{abstract}
The L.O.L. Surprise doll was created in 2016 by MGA Entertainment inspired by the YouTube trend of "unboxing" videos, in which children and adults open toys packages, or other objects, and show to the viewers how it works or what it does. Being a collectible toy with the possibility of more than a hundred surprise dolls, L.O.L. Surprise, which is a best seller, explores playing from the unwrapping of the several layers involved in the unboxing of the doll's package. The marketing of L.O.L. Surprise does not involve TV advertisements and all its strategy is focused on YouTube videos showing kids unboxing the toy. It is possible to perceive that opening the package, and consequently finding the doll, is part of the experience/play of L.O.L. Surprise. Not only is the rise of L.O.L Surprise a trend in Brazil but all around the world (FROMM, 2019), being an increasingly successful trend in last years (GREEN, 2018). This study aims at describing and analyzing the multimodal features of the layers of the doll's package, perceiving how the surprise element is constructed through it. Therefore, to analyze the layers of the package, we draw on Kress \& Van Leeuwen's Grammar of Visual Design (2006 [1996]) and its visual metafunctions, which derive from Halliday's Systemic Functional Linguistics (1978). The description and analysis reveal a stimulus to children's curiosity, enhanced by the interactive aspect perceived through the verbal and visual language, as well as a tendency towards consumerism and social media engagement.
\end{abstract}

KEYWORDS: Toys, multimodality, surprise, package, Grammar of Visual Design.

RESUMO: A boneca L.O.L. Surprise foi criada em 2016 pela MGA Entertainment inspirada pela tendência de vídeos de "unboxing" no YouTube, onde crianças e adultos abrem embalagens de brinquedos, ou outros objetos, para mostrar aos espectadores como funcionam ou o que fazem. Sendo um brinquedo colecionável, com a possibilidade de mais de cem bonecas surpresa, a L.O.L. Surprise, que é um sucesso de vendas, explora o brincar pela descoberta das várias camadas envolvidas no "unboxing" da embalagem da boneca. O marketing da L.O.L. Surprise não envolve anúncios de TV e toda a sua estratégia é focada em vídeos no YouTube mostrando crianças abrindo (e/ou descobrindo) o brinquedo. É possível perceber que abrir a embalagem faz parte da experiência/brincadeira da L.O.L. Surprise, e consequentemente encontrar a boneca. O aumento de vendas da L.O.L Surprise é uma realidade não apenas no Brasil, mas ao redor do mundo (FROMM, 2019), sendo uma tendência de sucesso crescente nos últimos anos (GREEN, 2018). Esta pesquisa tem como objetivo descrever e analisar os aspectos multimodais das camadas da embalagem da boneca, percebendo como o elemento surpresa é construído através delas. Portanto, para a análise das camadas da embalagem utilizaremos como suporte teórico a Gramática do Design Visual de Kress \& Van Leeuwen (2006 [1996]) e suas metafunções visuais, que derivam da linguística sistêmico-funcional de Halliday (1978). A descrição e a análise revelam um estímulo à curiosidade nas crianças, acentuado pelo aspecto interativo percebido através da linguagem verbal e visual, assim como uma tendência em direção ao consumismo e maior engajamento com as redes sociais

PALAVRAS-CHAVE: Brinquedos, multimodalidade, surpresa, embalagem, Gramática do Design Visual.

\footnotetext{
${ }^{1}$ Doutora em Inglês e Literatura Correspondente pela Universidade Federal de Santa Catarina (UFSC), com cotutoria na Universidade de New South Wales (UNSW), na Austrália. Professora Associada no Departamento de Línguas Estrangeiras Modernas (DLEM) e na Pós-Graduação em Lingüística (PROLING) da Universidade Federal da Paraíba (UFPB). Coordena o Projeto Multimodalidade e Infância por meio da Bolsa de Produtividade em Pesquisa (PQ2) do CNPq. Líder do Grupo de Pesquisa em Semiótica Visual e Multimodalidade (GPSM). Email: danielle.almeida@gmail.com.
}

2 Graduada em Letras/Inglês (2019) pela Universidade Federal da Paraíba (UFPB). Membro do Grupo de Pesquisa em Semiótica Visual e Multimodalidade (GPSM). Email: poliannaftorres@yahoo.com.br. 
Volume 14 - Número 2 - ago/dez de 2019

\section{Introduction}

In contemporary times, toys are related to childhood culture not only as objects of children's desire, but also because "they are produced according to social meanings which vary historically and culturally and, therefore, they convey different messages to children about the social world and the social practices that surround them" (CALDASCOULTHARD; VAN LEEUWEN, 2003). Considering Caldas-Coulthard and van Leeuwen's concept about the role of toys in childhood, one can look around so as to try to understand in which ways toys influence children in current times.

Fleming (1996) pointed out to the fact that it seemed inconceivable that the toy industry was not dependent on a popular culture which shaped and structured the meanings carried by toys. Decades later, the influence of popular culture in the toy industry is still very real, and it can be explored and perceived if one takes a good look at the most successful toys of a certain period.

MGA Entertainment created the L.O.L. Surprise dolls in 2016, inspired by the popular trend of unboxing videos, in which children and adults open products and/or packages and show to the viewers how it works or what it does. The secret dolls have been a best seller for the last couple of years in a worldwide meteoric rise (GREEN, 2018). L.O.L. Surprise dolls come inside a round-shaped package wrapped by several layers of plastic which lead the child through different surprises until they finally find the toy. As they are surprise collectible dolls, children do not know which of the more than 100 different dolls they will find.

L.O.L. Surprise has no TV advertisements, as all the marketing strategy is focused on YouTube videos, in which kids "unbox" the toy. In 2019, with the success of the brand, MGA has released other toys related to L.O.L. Surprise which do not follow the original surprise model. However, since the layered round-shaped model was the original success of the doll, it was the one chosen to be analyzed in this study.

Understanding that toys are embedded with social meanings which represent a certain period of time and have a huge impact on children, this study describes and analyzes the multimodal features of the layers of one package of the L.O.L. Surprise doll, in order to investigate how the design of the layers build the surprise element and its interactive implications to children.

The corpus for this study is a collection of 25 images of the 5 layers of the package of Series 2 Wave $2^{3}$ L.O.L. Surprise doll. In order to perceive how the visual and the verbal elements of the layers are involved in developing the surprise element, making the discovery process the main focus of the L.O.L. Surprise doll, the multimodal analysis resorts to Kress and van Leeuwen's representational, interactive and compositional metafunctions ${ }^{4}$ described in their Grammar of Visual Design (2006 [1996]).

Our objectives have been (1) to describe and analyze the layers of L.O.L. Surprise's package through the Grammar of Visual Design (2006 [1996]); (2) to identify how L.O.L. Surprise's multimodal aspects contribute and enrich the surprise element built through the process of discovery; and (3) to reflect upon and report the implications of the attached interactive meanings of L.O.L. Surprise's package with children and consumerism. The next section deals with the detailed information about the L.O.L. Surprise doll.

\footnotetext{
${ }^{3}$ The L.O.L. Surprise dolls have different Series, which are different collections, and even inside of a Series, there is the possibility of more than one Wave. A Wave adds dolls which are still not revealed, therefore, if a Series has 2 Waves, it means some dolls were revealed in the first Wave and some in the second, including new dolls in an already existing Series.

${ }^{4}$ Representational, interactive and compositional metafunctions are explored and explained in Section 3.
} 
Volume 14 - Número 2 - ago/dez de 2019

\section{The L.O.L. doll and its surprise element}

In 2016, the L.O.L. Surprise doll was created by toy manufacturer MGA Entertainment being categorized as a collectible toy. Its appearance is very diverse. There are dolls with many different shades of skin color, different types of hair, as well as different fashion styles. The focus on fashion styles and colors used can be traditionally connected to a predominant female audience. However, in 2018, MGA Entertainment added the first male doll to the L.O.L. collection, Punk Boi, which can be regarded as an attempt of the company to expand the target audience of consumers.

Another fact about the L.O.L. Surprise dolls is that it is possible to find in their manuals - which come with the dolls - their own doll classification: they can be "popular", "fancy", "rare" or "ultra-rare". The classification is an aspect of great interest to children, since it stimulates their desire to have the "ultra-rare", which could be regarded as a consumption design strategy. In order to have the rarest dolls, children have to consequently buy more dolls in order to find them, stimulating consumerism.

After peeling each of the layers, the child finds different surprises, namely: a secret message (which is a clue to the doll's name), stickers, a bottle, shoes, an outfit, and finally, inside the package, an accessory and the doll, all in miniature sizes. There are more than 100 surprise dolls, among different Series and Waves.

MGA Entertainment created the L.O.L. Surprise doll in adaptation to the new digital era. Therefore, MGA developed a different strategy. The dolls are not advertised through TV commercials, as it was common in the past decades, but through social media, since this strategy has become increasingly more powerful when it comes to contemporary marketing and advertising.

The strategy worked, as the L.O.L Surprise in present days ${ }^{5}$ has its advertising and campaign based on social media, with 1.135.658 subscribers on its YouTube channel, 528.544 and 176,151 followers on its Instagram and Facebook, respectively. The doll not only has YouTube as its main advertising platform, it was created inspired by the YouTube trend of unboxing videos, according to Marsh (2016, p. 375),

these are videos in which commercial goods are unwrapped and they have become very popular, with the most frequently viewed channels attracting billions of views. Those aimed at children focus on the unwrapping of toys or artefacts such as collectible cards and surprise/Kinder eggs.

The unboxing trend aligns with Kline's (1993, p. 241) affirmation about advertisements of how "kids liked to watch other kids having fun, and through the psychological process of evaluative transfer they would associate this pleasure with the product". Therefore, by watching other children opening the toys and playing with them, the child experiences an associative pleasure.

However, there seem to be different opinions about the ultimate result of the consumption of unboxing videos. In their studies, Marsh (2016), and Craig and Cunningham (2017), explore the different opinions and perspectives about the unboxing trend, which could either view it as a marketing strategy to stimulate consumerism, or as new form of entertainment to children. Therefore, there is not an agreement among researchers about whether the unboxing trend is ultimately positive or negative, but it is certain that not only was L.O.L. inspired by the trend but it also continues to inspire it by stimulating children to record their own unboxing videos.

\footnotetext{
${ }^{5}$ The data about L.O.L. Surprise number of followers and subscribers was collected on August $18^{\text {th }}, 2019$.
} 
Volume 14 - Número 2 - ago/dez de 2019

The creation of L.O.L. envisioned the unboxing of the doll, and consequently it became a sensation with millions of views on its YouTube videos. The "unboxing" videos of L.O.L. dolls are even more popular because the kids who buy the dolls are encouraged to record their own videos and post them on social media.

Nevertheless, the L.O.L. doll became not only an Internet sensation, but also a best seller in many countries, such as Australia, the United States, the United Kingdom and New Zealand, being considered in 2017, "this year's hot toy" (BHATTARAI, 2017) or "toy of the holiday season" (WHITE, 2017). In 2018, L.O.L. Surprise won the Toy of The Year (TOTY) Award, alongside Fingerlings by WowWee USA, Inc, establishing it as a successful, and therefore, relevant doll of our contemporary times. One of the elements which could be attributed to the worldwide success of L.O.L. is its "surprise" element, which stimulates children's curiosity.

Since the toy's inspiring idea was its "opening", the discovery process plays a huge part in its composition and how the L.O.L doll interacts with children. The discovery is emphasized through the surprise element. Taking that in consideration, one could understand that the round-shaped package, and the way it is supposed to be opened, can be related to a "different shaped appeal", since dolls' boxes are traditionally rectangle-shaped, contributing to the development of the surprise with an unusual way of opening.

Since the buyer already knows that there is a surprise involved in the process of opening the L.O.L. package, there is an anticipation which requires from designers to influence customers' expectations before the experience itself (DIXON et al, 2017). Such role is played by the five layers which involve the package, since they will develop this anticipation interacting with the child and creating the whole experience of opening the surprise doll.

When observing the design of L.O.L. Surprise's package and understanding from this perspective the role played by the layers, one could say that the opening (or unboxing) of the doll is already part of the play. As Fleming (1996) stated, "toys are infinitely adaptable and can take on meanings other than those they originally came with, and indeed any object can temporarily become a toy." (p. 67). Therefore, the layers of the package could "temporarily become a toy" in the child's process of discovery through the unboxing of the doll.

According to Kim and Mattila (2013), "providing an explanation for a surprise event is not only useful to control customers' expectations but also helpful in enhancing customer delight" (p. 366). It is possible to relate this to the L.O.L. Surprise toy, since the previous information about the seven surprises discovered through the layers provoke this anticipation which continues to be built until the discovery of the doll.

In order to understand how the package layers of L.O.L. Surprise enhance anticipation and build children's expectations while unwrapping the toy, the layers of the package of one L.O.L. Surprise doll are analyzed through the Grammar of Visual Design (2006 [1996]), in terms of its representative, interactive and compositional metafunctions, to be explored in the next section.

\section{The Grammar of Visual Design}

In order to analyze visual images, we draw on Kress \& Van Leeuwen's Grammar of Visual Design (2006 [1996]), a theory that has been evolved from Halliday's Systemic Functional Grammar. As the authors claim in their book Reading Images (2006 [1996]), images are not only aesthetic and expressive, but also structured in social, political and communicative dimensions (KRESS; VAN LEEUWEN, 2006 [1996]). The Grammar of Visual Design proposes three metafunctions through which an image can be perceived and, therefore, analyzed: Representational, Interactive and Compositional. The three 
Volume 14 - Número 2 - ago/dez de 2019

metafunctions are perspectives which coexist, through which it is possible to analyze different aspects of any visual representation.

The Representational metafunction is portrayed through the participants, processes or objects represented in the semiotic mode and the meanings that are built through this representation, be it through a process of interaction or classification. This metafunction can be divided between narrative and conceptual representations. Narrative representations are characterized by the presence of vectors which connect the participants, the vectors are elements which indicate action, reaction, mental or verbal processes. In action processes the participants are regarded as Actors and the Goal. In the reaction process the participants are called Reactor and Phenomenon. Mental and Verbal processes are characterized by different kind of vectors, thought balloons and dialogue balloons.

Conceptual representations, on the other hand, do not entail the presence of vectors and can be classified as classificational, analytical or symbolic processes. In classificational processes the participants are the Subordinate and Superordinate. In the analytical participants are named as Carriers and Possessive Attributes. Participants in symbolic processes are Carrier and Symbolic Attributes.

The Interactive metafunction is perceived through the interactions between the represented participants and the viewer (interactive participant), which can be perceived through positioning, angles, shot distance and modality. This metafunction contemplates the following dimensions: contact, social distance and attitude. Contact is established between the participants and the viewer through a vector coming from the participants' eyeline/gaze. A contact can be of a demand type or of offer type. The social distance is analyzed through the distance in which the participants are visually represented which can be in a close shot, medium shot and long shot.

Attitude is related to the angle through which the represented participants are positioned, determining the perspective through which they are seen by the viewer. Attitude can be determined by frontal, oblique or vertical angles. A frontal angle establishes a sense of involvement with him/her, while the oblique angle establishes a sense of detachment from him/her (ALMEIDA, 2006). A vertical angle determines power connected with the high (interactive participant (viewer) has power over the represented participant), low (represented participant has power over the interactive participant) or eye level angle (no power difference between participants).

The last metafunction, the compositional one, is defined by the positioning of the visual elements, the way in which the representational and interactive elements are thus integrated creating meaning (KRESS; VAN LEEUWEN, 2006 [1996]). The compositional metafunction can be contemplated through information value, salience and framing. Information value is related to the placement of the elements in the different "zones" of the image, left and right, top and bottom, centre and margin, and how the different positions convey different meanings to the elements.

Salience creates a hierarchy of importance among the elements by the use of contrasts of color, size, background or foreground placement. Framing is analyzed through the presence or absence of frames or lines which can connect or disconnect elements in the image, making the visual representation strongly or weakly framed, creating a sense of a more connected or disconnected unit of information (KRESS \& VAN LEEUWEN, 2006 [1996]).

Having explained the systems of signification of the Grammar of Visual Design's representational, interactive and compositional metafunctions, we assume that the theory is adequate to explore the proposed object of research. Therefore, in the next section the layers of L.O.L Surprise's package are analyzed in order to perceive how this anticipating experience is built enhancing the surprise element through its multimodal features. 
Volume 14 - Número 2 - ago/dez de 2019

\section{Analysis}

Through the process of discovery of the doll, the peeling of different layers plays a role in contributing with curiosity in the revealing process. Each one of the five layers of one package are analyzed below according to the representational, compositional and interactive metafunctions in order to disclose how they contribute to the surprise element. The package analyzed is from L.O.L. Surprise Series 2 Wave 2, donated to our research group by a child who had already opened the package. The Series 2 is the last Series that follows the original format of discovery (one surprise by layer), being, therefore, the last (more recent) Wave of L.O.L. Surprise which is "unwrapped" in the original format/discovery process.

In this section the layers analyzed are exposed through pictures taken by the us, the researchers. The first layer of the package is the first component that the child or adult - since sometimes parents are the ones buying the toy - sees. Since the doll does not come in a case, the first layer works as a "box" by containing all the information about the product, as it is possible to see in Figure 1.

\section{Figure 1 - First layer}
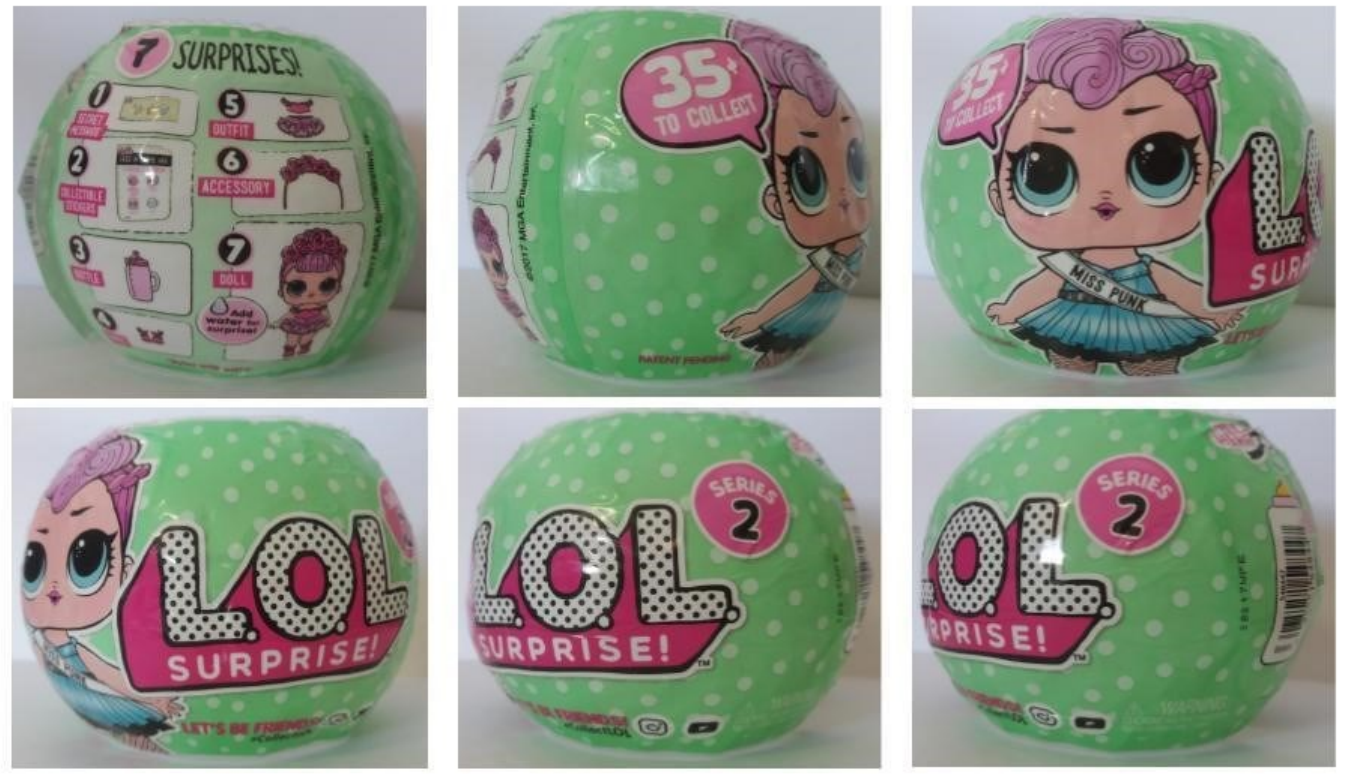

Source: Personal file.

The first layer (Figure 1) brings information about the 7 surprises which come inside the package: the doll's logo, information about which series it belongs to, code bar, security warning, symbols that indicate their presence on social media (Instagram and YouTube) and a representation of a L.O.L. Surprise doll through the image of the Miss Punk doll. The represented doll carries a verbal process through a speech balloon where it is written " $35+$ to collect". The fact that the image portraits the doll itself saying it, confirms that the first layer works as a "box" to this product, as it exposes the product information.

In compositional terms one aspect that calls our attention is the salience given to the doll's eyes. L.O.L. Surprise does not seem to replicate the proportions of a human, and the eyes are much larger when compared to other elements of the doll's face, such as nose or mouth. Kress and van Leeuwen (2006 [1996]) comment on differences related to eye size in dolls traditionally related to boys or girls. They state that "the eyes of 'girls' dolls [...] tend to be large and highly detailed. While boys are steered towards a more manipulative relation to 
their dolls, for the girls the look, the interactive dimension, is made to matter more." (p. 251). Even though L.O.L. Surprise does not explicitly categorize their dolls as aimed to a specific female audience, it is worth mentioning that the larger eyes in dolls reveal that the doll appeals to the interactive dimension, an issue yet to be explored in the analysis.

In relation to its interactive meanings, one can perceive that there is an interaction established with the viewer, a child or an adult, "talking" to her/him and also by establishing a contact of demand as the doll looks directly to the viewer, as well as by the positioning of the doll in a medium shot, adding proximity to the viewer, though not completely intimate and known, because it is still a surprise doll. The frontal angle in which the doll is depicted also contributes to the establishment of a relationship of familiarity with the viewer by its characteristic of involvement, which continues to be reinforced through the peeling of the subsequent layers.

Such an interactive aspect of the package also gets reinforced through the kinetic aspect of the unboxing process. According to Caldas-Coulthard and Van Leeuwen (2003), "the kinetic design of larger dolls such as teddy bears is not so much oriented towards allowing the children to make the dolls do things, as towards allowing the children to directly interact with the dolls, so that the dolls become the objects of the child's actions" (p. 3). Therefore, the opening process, through the peeling of the layers, makes L.O.L. Surprise an "object of the child's actions", adding interactive value to the toy.

Through the compositional metafunction one can perceive the doll as the most salient element of the layer. Because of its round shape one cannot be assertive about which element is the centre of layer. However, Kress and Van Leeuwen (2006 [1996]) affirm that "regardless of where they are placed, salience can create a hierarchy of importance among the elements, selecting some as more important, more worthy of attention than other" (p. 201).

Even though the doll is not the central element of the layer, she can be considered the most important component through salience. She is foregrounded through size, and hair color which contrasts with the green background. At the same time, the dolls and the logo focus on the main object of desire to children, which is the L.O.L. Surprise doll. After peeling the first layer, the child ${ }^{6}$ finds a secret message which should help him/her guess which doll is inside. The next layer (Figure 2) contains some information about the product. This layer has a different kind of representation when compared to the previous one and the subsequent ones, as it is possible to see in the following images.

Figure 2 - Second layer
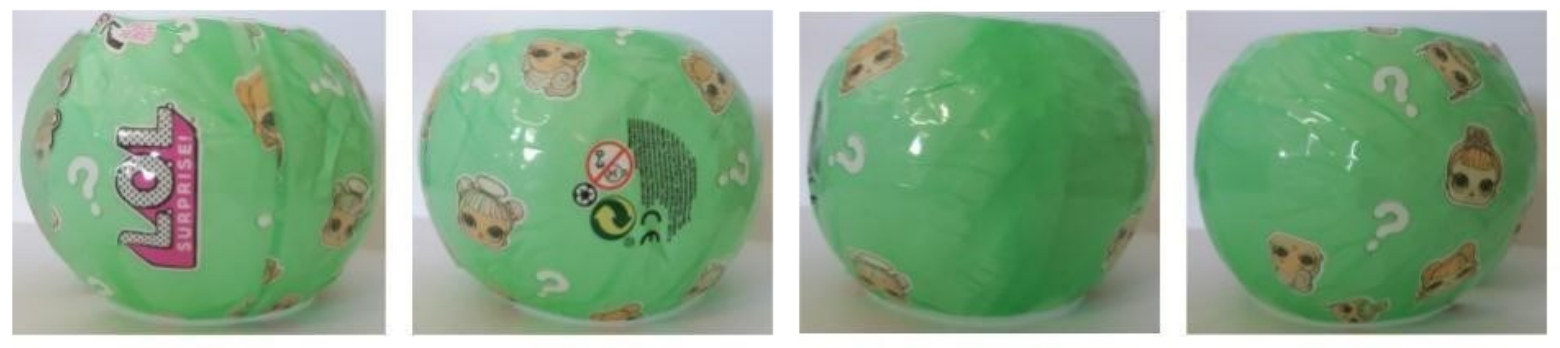

Source: Personal file.

\footnotetext{
${ }^{6}$ From now on the participant referred to as "the viewer", according to the Grammar of Visual Design (2006 [1996]), is referred to as "the child". Until this point the viewer could be a child or adult observing the closed package, but since children are the target audience of the toy, we assume that the subsequent layers are observed by the child who peels the layers opening it.
} 
Volume 14 - Número 2 - ago/dez de 2019

The green background is filled with question marks and images of heads of some of the L.O.L. Surprise dolls. It is possible to perceive a conceptual representation of the dolls through symbolic process. One could interpret the question marks as symbolic attributes which enhance the "surprise element" as the most important characteristic of L.O.L Surprise, stimulating the child's curiosity to try to figure out which doll they are about to find inside the package. The doll heads could be read as the carriers of the mystery related to the surprise doll, representing the many possibilities of dolls which can be found inside the package. The symbolic process encapsulates the mystery which makes the child wonder about which doll they could come across inside the package, stimulating curiosity and imagination.

The third layer (Figure 3) has a change in its background color, now a pastel pink background with many different baby bottles and the depiction of the L.O.L. Surprise doll, Court Champ.

Figure 3 - Third layer
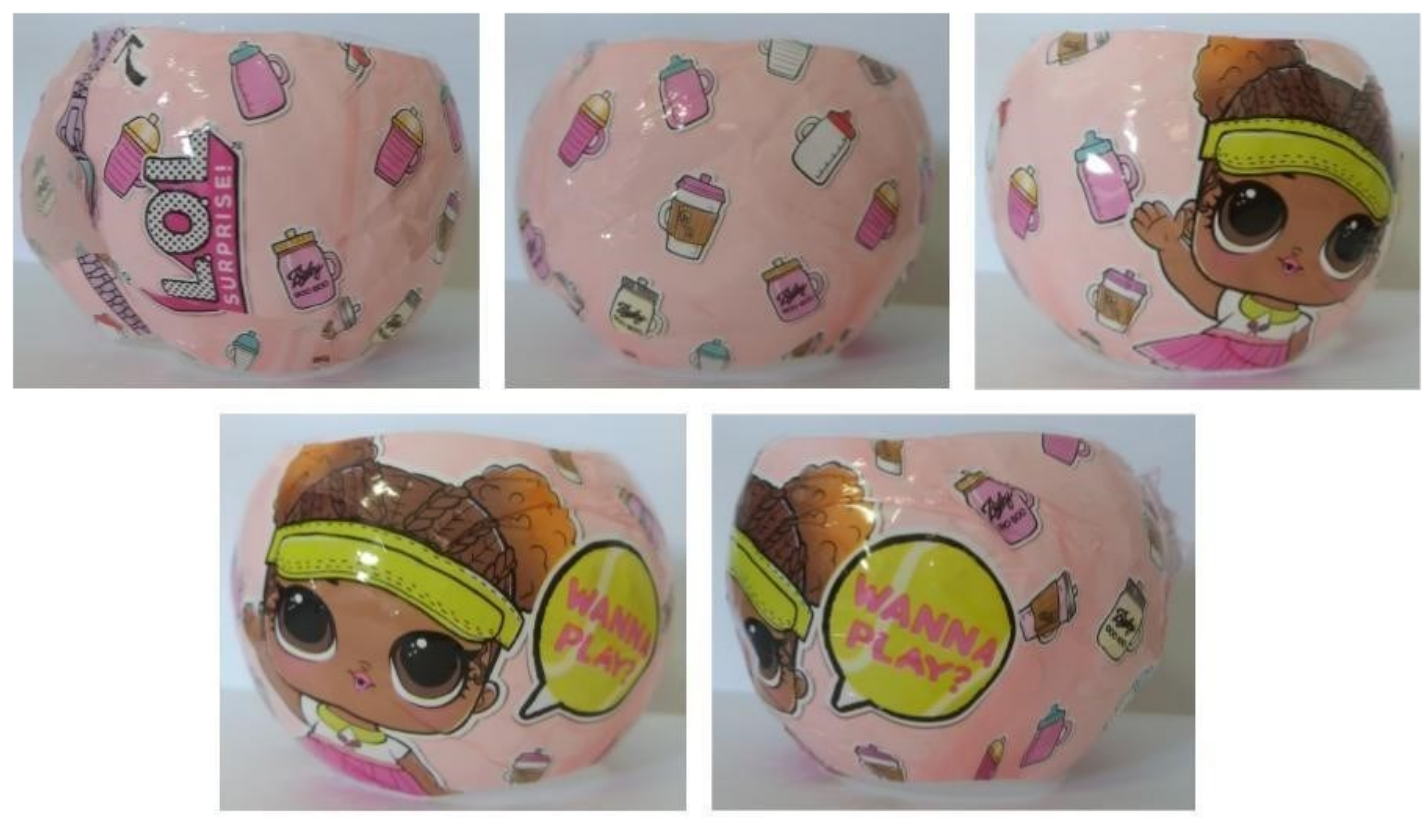

Source: Personal file.

In interactive terms, this layer is represented with doll Court Champ in a medium shot, establishing an interaction with the child through a frontal angle, by looking directly at her/him via a demand gaze. The doll is the main element of the layer, therefore she becomes the main focus of the image not only through her conspicuous size and positioning, but also through the contrast of her brown skin and hair color with the pastel pink colored background. The positioning is very similar to the doll represented in the first layer, although at this point there is a change in the verbal process. While in the first layer, Miss Punk talks to the buyer about the other 35 possibilities of dolls to collect, Court Champ establishes a stronger interaction with the child by asking a question, "WANNA PLAY?".

While in the first layer the verbal process gives extra information about the product, this one directly interacts with the child who is already "unwrapping" the doll. It is possible to perceive the informal use of the language and the establishment of interaction since it is targeted at children, as if it were the doll herself who were asking the child a question. By asking, "WANNA PLAY?" the doll reinforces her "desire to play" with the child, while curiosity continues to be stimulated through the unveiling of L.O.L. Surprise's layers. 
Volume 14 - Número 2 - ago/dez de 2019

Figure 4 - Fourth layer
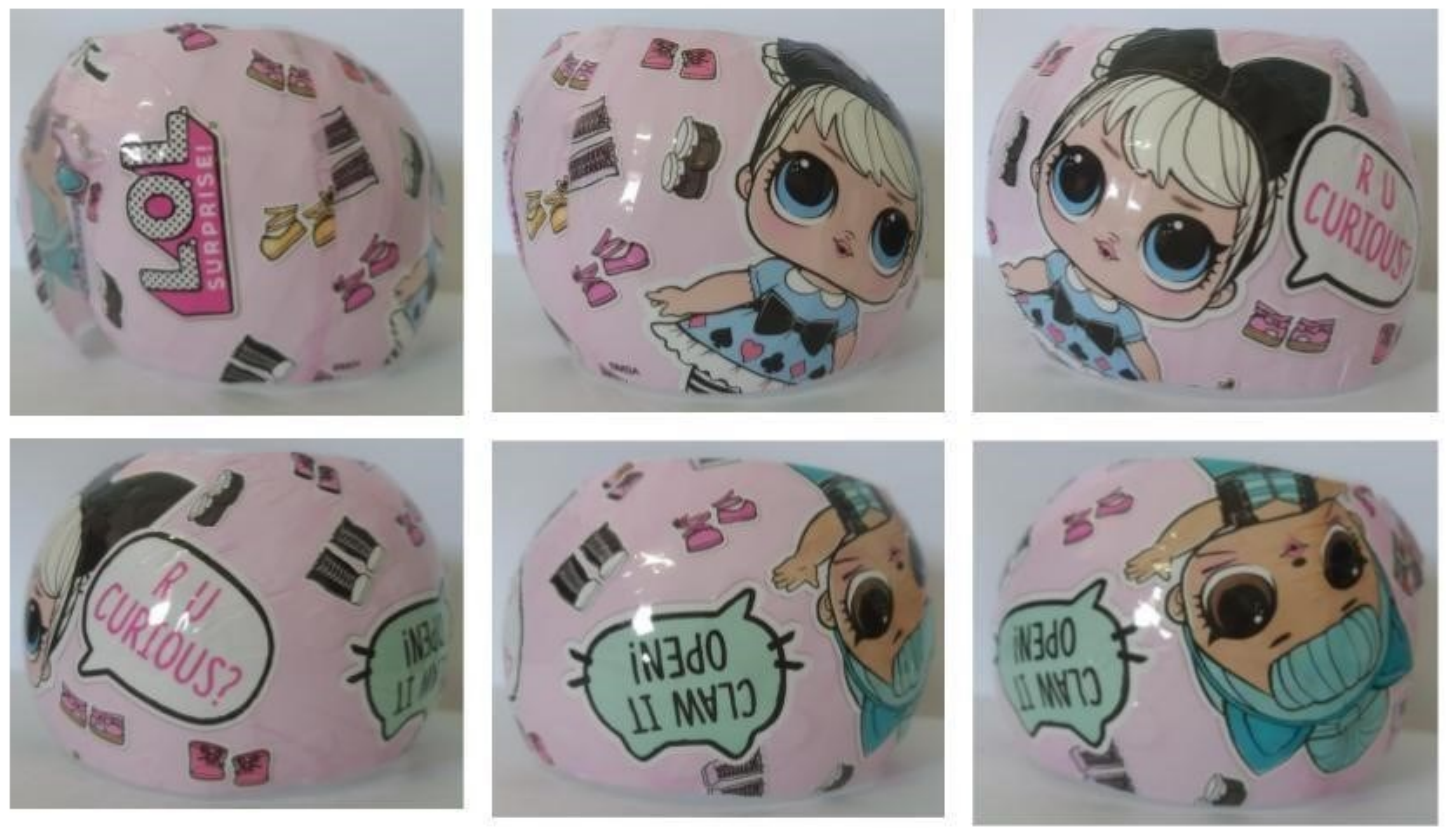

Source: Personal file.

In interactive terms, the fourth layer (Figure 4) depicts not only one but two dolls establishing contact with the child through the same kind of visual representation as the previous one. The dolls are placed in a medium shot, establishing a demanding interaction through the gaze and frontal angle, by looking directly at the child. They are positioned in different angles, so one of them looks upside down, depending on how the round shaped package is positioned. In the pictures used for this article, Troublemaker is the one represented upside down in relation to Curious Q.T.

The pastel pink background has many different pairs of shoes represented, since it is the next accessory to be revealed. There are two different verbal processes happening. The first verbal process out is the one happening through the L.O.L. doll Curious Q.T.'s question to the child, "R U CURIOUS?". We already know that the use of questions is an attempt to establish a stronger connection with the child, therefore developing interaction and clearly inducing the child's curiosity and excitement for the doll.

As the child goes on unwrapping the layers it is also possible to perceive the continuous use of the informal language. The use of an informal register tends to follow the trends of Internet language such as "R U" instead of "Are you". The second verbal process establishes a connection with the doll who is "speaking". One can perceive that the speech balloon has the shape of a cat, which can be associated with the "cat-themed" doll who is speaking, Troublemaker, since her features and accessories resemble a cat. Following the "cat theme" the speech balloon presents the words "CLAW IT OPEN!", which continues to stimulate the child to move forward and continue in search of the surprises. 
Volume 14 - Número 2 - ago/dez de 2019

\section{Figure 5 - Fifth layer}
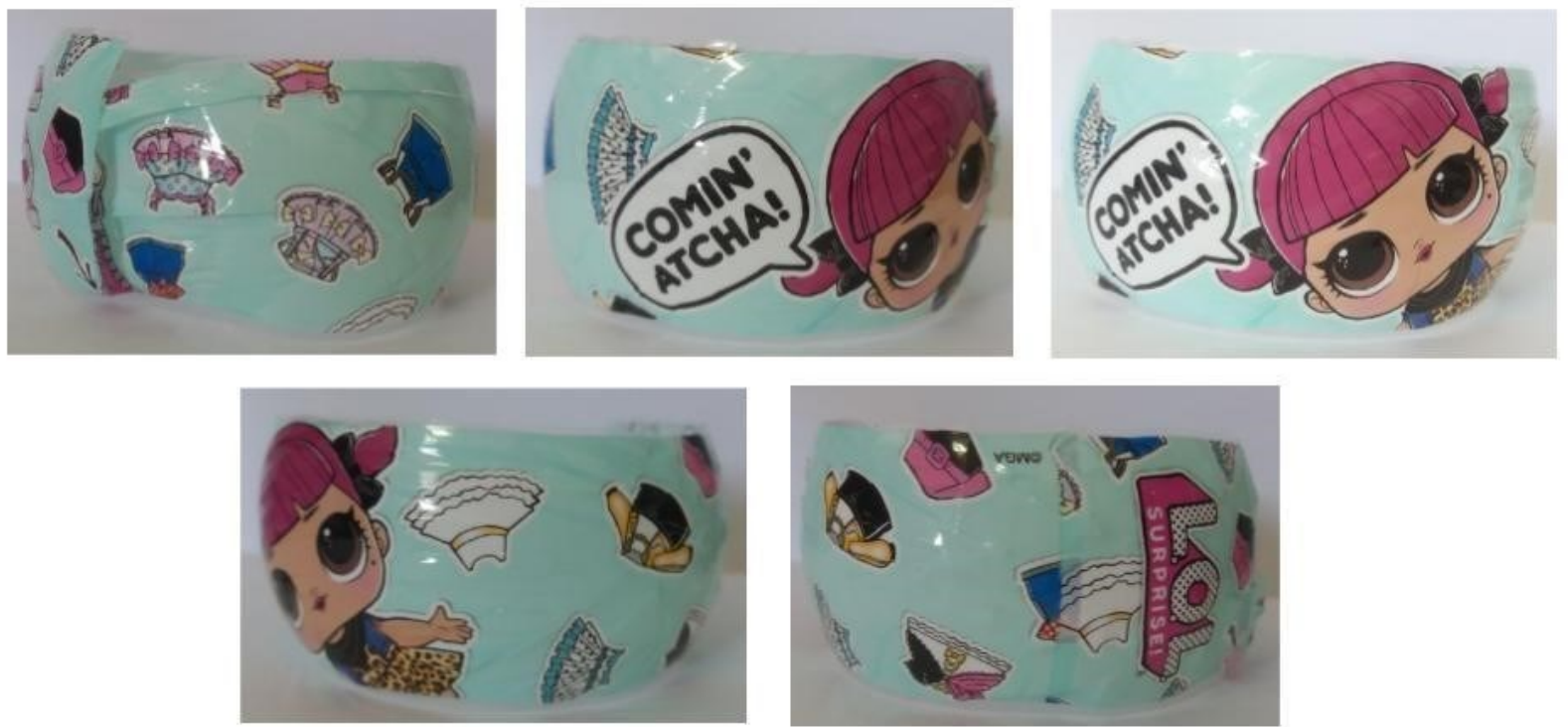

Source: Personal file.

As it is possible to see in the previous images (Figure 5), the fifth and last layer is smaller than the others. Through its pastel blue background, it is possible to see different outfits, which is the next of the seven surprises to be revealed, followed by the last accessory and the doll. Cherry is the L.O.L. Surprise doll represented in the package layer, and she follows the same interactive perspective previously represented by the other dolls (demand, medium shot, frontal angle).

However, being the last layer before finding the doll, the verbal process does not bring questions or instructions, but that seems to represent what the doll inside of the package would say to the child, "COMIN' ATCHA!", which means "Coming at you!". Again, the doll establishes an interaction with the child, through the same informal register, warning the child that they are close, and that it is "coming" in his/her direction, which means her/him is close to finding the doll.

It is possible to perceive a pattern of background pastel colors through all the layers, which contrasts with the colors of the doll's hair, skin or clothes, which are most of the time more vibrant and saturated. It could be argued that the representation of the dolls tends to follow a more adventurous and exuberant fashion, which contributes to adding a positive value to the toy. The flowchart below depicts the main findings of the analysis of the layers of L.O.L. Surprise's package. 
Volume 14 - Número 2 - ago/dez de 2019

Figure 6 - Flowchart

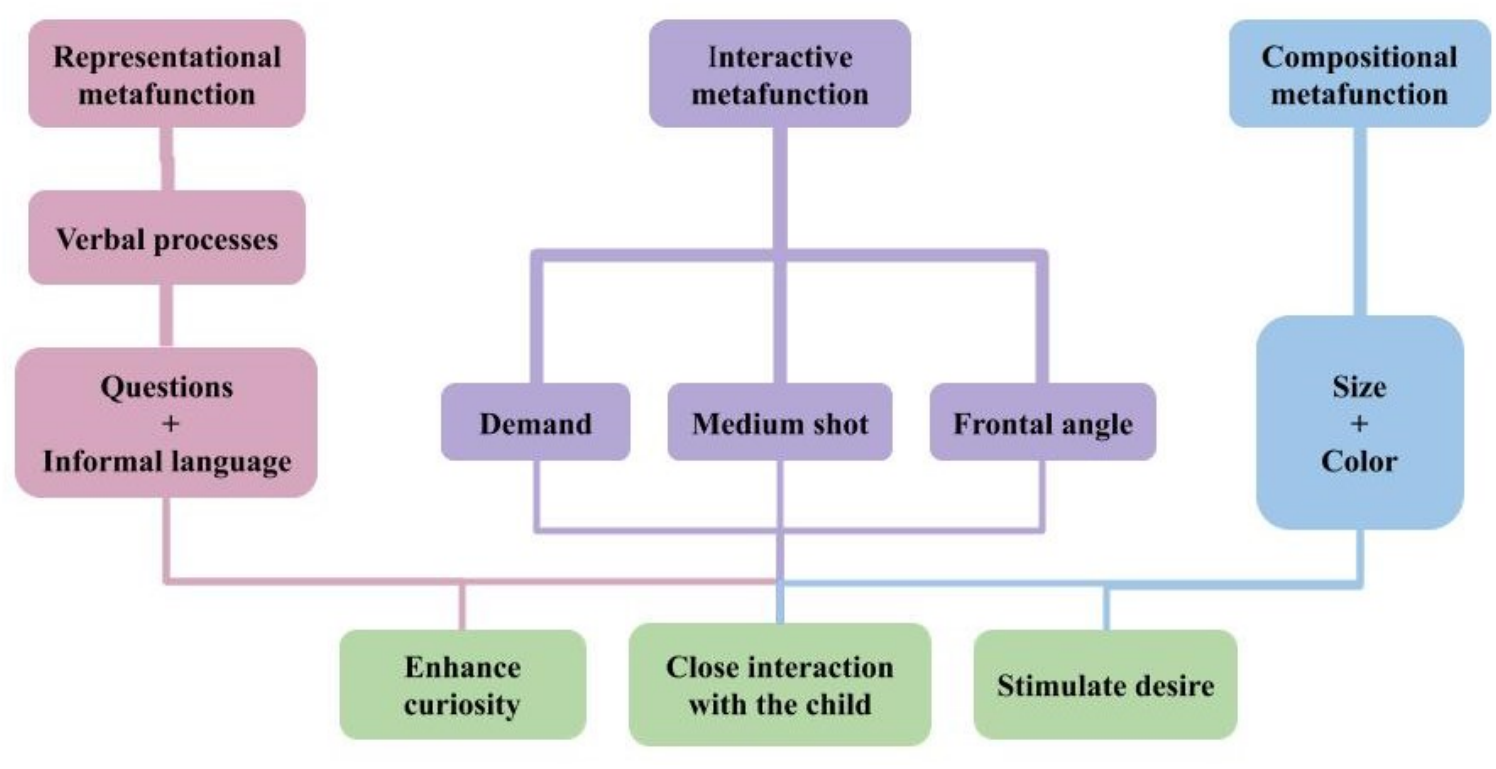

Source: Personal file.

The analysis reveals that it has been possible to perceive that the package attracts the child's attention through its attached interactive meanings and the exploration of the interaction between the doll and the child through its verbal processes. Curiosity is also provoked during the whole process of discovery of the round-shaped package, through the unboxing itself.

Despite knowing that there is a surprise doll inside the package, each layer continues to promote the desire through the positioning of the doll, which aims to establish an interactive relationship with the child and the colorful and salient composition of each one of the layers. The process of peeling the layers is a journey of anticipation which children go through in order to reach the climax with the discovery of the doll.

\section{Final Considerations}

Through the analysis heretofore presented, it has been possible to observe the fulfillment of the objective (1) to describe and analyze the layers of L.O.L. Surprise's package through the Grammar of Visual Design (2006 [1996]). Revealing by the representational metafunction the verbal processes via informal questions, through the interactive metafunction, contact of demand, medium shot and frontal angle, and by the compositional metafunction, the salience through size and color.

Such description helped (2) to identify how L.O.L. Surprise's multimodal aspects contribute and enrichen the surprise element built through the process of discovery, by revealing how the anticipation of the surprise element is built through the representational, interactive and compositional elements of the layers. A sense of familiarity and interaction with the child is fostered through verbal processes conveyed by the use of informal language and the enhancement of curiosity by means of questions, as well as the positioning of the doll stimulating interaction and desire, all of which while the child unwraps and discovers the surprises before reaching the doll itself.

Understanding that there is a surprise peak when the child finally finds the doll, although it fades away as soon as it is over, it is possible (3) to reflect upon and report the 
Volume 14 - Número 2 - ago/dez de 2019

implications of the attached interactive meanings of L.O.L. Surprise's package with children and consumerism. Therefore, one could say that the main element of L.O.L. is the surprise, and that its discovery process is the most important moment of acquiring the toy. After the doll is discovered, the surprise is over, and since the surprise is what attracts children to this toy, because these dolls are collectible, it is possible to say that they stimulate consumerism.

Pinto (2016) argues that when play becomes about buying and accumulating, it reinforces lessons about accumulating things just for the sake of it, not for the beauty of things not mass-produced. Therefore, L.O.L. Surprise opens space for a very necessary discussion about the influence of accumulating, collectible toys and consumerism in children.

The success of L.O.L. Surprise is not limited to the surprise element related to consumerism. It is important to acknowledge the always growing influence of social media, since the doll is extremely popular for its unboxing videos. It is still unknown whether these videos will a be quick trend or if they will establish a new form of entertainment, but they definitely create a huge amount of content to be explored and researched. The surprise has an appeal that goes beyond the actual toy, which gets expanded through the digital world. Therefore, it would not be surprising to predict the continuity of this tendency of engagement between toys and social media throughout times. Researching about toys contributes to understanding to a greater degree the ideas and contexts surrounding contemporary childhood, which makes us more aware and sparks new reflections about our society.

\section{References}

ALMEIDA, Danielle. B. L. Icons of contemporary childhood: a visual and lexicogrammatical investigation of toy advertisements. 2006. Tese (Doutorado em Letras) - Universidade Federal de Santa Catarina, Santa Catarina.

BHATTARAI, Abha. 'Unboxing' this year's hot toy: The L.O.L. Surprise. The Washington Post. 2017. Disponível em: <https://www.washingtonpost.com/business/economy/unboxingthis-years-hot-toy-the-lol-surprise/2017/11/06/80172b32-b436-11e7-a908a3470754bbb9_story.html?utm_term=.2922133b5263>. Acesso em: 28 de agosto de 2019. CALDAS-COULTHARD, Carmen Rosa; VAN LEEUWEN, Theo. Teddy bear stories. Social Semiotics, v. 13, n. 1, p. 5-27, 2003.

CRAIG, David; CUNNINGHAM, Stuart. Toy unboxing: living in a (n unregulated) material world. Media International Australia, v. 163, n. 1, p. 77-86, 2017.

DIXON, Michael J. et al. Surprise, anticipation, and sequence effects in the design of experiential services. Production and Operations Management, v. 26, n. 5, p. 945-960, 2017.

FLEMING, Dan. Powerplay: Toys as popular culture. Manchester: Manchester University Press, 1996.

FROMM, Jeff. The Ever-Changing MGA Entertainment. Forbes. 2019. Disponível em: $<$ https://www.forbes.com/sites/jefffromm/2019/03/13/the-ever-changing-mgaentertainment/\#1b45339321d4>. Acesso em: 28 de agosto de 2019.

GREEN, Dennis. A doll with a bizarre name has become the biggest toy of the holiday season by taking over YouTube with unboxing videos. Business Insider. 2018. Disponível em: $<$ https://www.businessinsider.com/lol-surprise-dolls-hottest-toy-holiday-2018-11>. Acesso em: 17 de agosto de 2019.

HALLIDAY, Michael A. K. Language as social semiotic: The social interpretation of language and meaning. London: Edward Arnold, 1978. 
Volume 14 - Número 2 - ago/dez de 2019

KIM, Min G.; MATTILA, Anna S. Does a surprise strategy need words? The effect of explanations for a surprise strategy on customer delight and expectations. Journal of Services Marketing, v. 27, n. 5, p. 361-370, 2013.

KLINE, Stephen. Out of the Garden: Toys, TV, and Children's Culture in the Age of Marketing. London: Verso Press, 1993.

KRESS, Gunther; VAN LEEUWEN, Theo. Reading images: The grammar of visual design. London: Routledge, 2006 [1996].

MARSH, Jackie. 'Unboxing'videos: co-construction of the child as cyberflâneur. Discourse: Studies in the cultural politics of education, v. 37, n. 3, p. 369-380, 2016.

PINTO, Laura E. Collect'em all: Gender, consumerism and the Shopkins phenomenon. Our Schools Our Selves. Ottawa: CCPA,2016.

WHITE, Martha. All About L.O.L. Surprise! Big Surprise, the Hardest-to-Get Toy of the Holiday Season. Money. 2017. Disponível em: <http://money.com/money/5006122/lolsurprise-big-surprise-toy-craze-where-to-buy/>. Acesso em: 28 de agosto de 2019. 